\title{
FINITE ELEMENT ANALYSIS OF THE BEHAVIOUR OF A CRACK IN THE ORTHOPEDIC CEMENT
}

\author{
Ali Benouis \\ Djillali Liabes University of Sidi Bel-Abbes, Mechanics and Physics of Materials Laboratory, Larbi Ben Mhidi, Algeria \\ ABDElKader Boulenouar \\ Djillali Liabes University of Sidi Bel-Abbes, Mechanical Engineering Department, Laboratory of Materials and Reactive \\ Systems, Larbi Ben Mhidi, Algeria; e-mail: aek_boulenouar@yahoo.fr
}

BOUAlEM SERIER

Djillali Liabes University of Sidi Bel-Abbes, Mechanics and Physics of Materials Laboratory, Larbi Ben Mhidi, Algeria

\begin{abstract}
In this paper, the finite element method is used to analyse the crack behaviour in the orthopedic cement of the total hip replacement by computing the stress intensity factors (SIFs) arround the crack tip. In this work, three cases are studied: crack emanating from a cavity, interaction effect of the crack emanating from a cavity with another cavity and the interaction effect of two cracks emanatingfrom two cavities. The stress intensity factors under mixed mode problems at the crack tip are computed for three zones of prosthesis: proximal, median and distal. The obtained results show that the crack initiated from a micro-cavity in the distal zone of cement can be propagated at the same time by opening and shearing of its lips. It is contrary to that initiated in the proximal zone which cannot be propagated. The mechanical behaviour of cracks in the medial zone depends of the crack initiation position.
\end{abstract}

Keywords: stress intensity factor, crack, cavity, orthopedic cement

\section{Introduction}

Over estimated 800000 total hip replacements are being performed worldwide annually (Jasty et al. 1991; Leroy 1992). Primary hip arthroplasty is subjected to failure due to the loosening of the implant or the prosthetic cup. $15 \%$ of the hip arthroplasty today are revision operations. A successful surgical procedure is developed where a ball-socket structure is used to replace the deceased or damaged hip joint. The replacement cup socket is usually attached to pelvis by acrylic bone cement which consists of a solid component of polymethylmethacrylate (PMMA) powder and a liquid component of monomethylmethacrylate (MMA). After mixing, polymerization takes place and within a few minutes of application to the bone cavity, the mixture becomes solid (Poitout, 1992; Li et al., 2002). The presence of a defect in the cement during mixing can locally lead to a region of stress concentrations producing possible fracture of the cement and consequently the loosening of the prosthetic cup. There are almost three kinds of defects: porosities, inclusions and cracks.

It is known that cracks are the most dangerous defect because of the presence of stress intensity on their front. The majority of cracks identified in the orthopaedic cement are (Hertzler et al., 2002; Bachir Bouiadjra, 2007): cracks initiated at porosities, cracks initiated during cement withdraw and cracks initiated at the junction between the bone and cement or between the cement and cup.

In literature, numerical works have been devoted to study the mechanical behaviour of cracks in the orthopedic cement: Benouis et al. (2015) presented numerical modeling of the 
crack propagation trajectory in the cement of reconstructed acetabulum. The direction crack was evaluated as a function of the displacement extrapolation technique and the strain energy density theory. Benouis et al. (2015) investigated the 3D-FE method to analyse the distribution of equivalents Von Mises stress around a cavity located in the bone cement polymethylmethacrylate (PMMA). The results showed that the micro-porosity located in the proximal and distal zone of the prosthesis was subject to a higher stress field. Sahliet al. (2014) studied damage of the orthopedic cement around the micro-cavity and estimated the length of the crack emanating from the microcavity for each position of the human body. The results showed that the damaged area was influenced by the cavity shape. Oshkour et al. (2013) investigated the X-FE method to analyze the behaviour of the internal circumferential cracks located in the cement layer of the cement-prosthesis interface during the main phases of the gait cycle. Benbarek et al. (2013) presented a numerical analysis of the crack growth path in the cement mantle of the reconstructed acetabulum. The maximal circumferential stresses criterion was used to determine the direction of the crack emanating from a micro-void in the cement layer. Bouziane et al. (2013) showed that the stress intensity factor evaluated for a crack emanating from an inclusion was higher than the crack emanating from a cavity. Ouinas et al. (2012) used the FEM to analyze the influence of the presence of microvoid and a crack emanating from the microvoid on the fracture behavior of bone cement. Flitti et al. (2010) analyzed the propagation criteria of cracks to predict the failure behaviour of cemented hip prostheses under monotonic loading conditions. That analysis was carried out on various zones of the cement along the bone, namely the proximal, the medial and the distal positions. Benbarek et al. (2007) investigated the FE method to analyse behaviour of the crack emanating from a microvoid by computing the SIFs at the crack tip. Taylor et al. (2003) used analytical and numerical methods to predict damage of the bone.

The use of crack propagation laws based on the stress intensity factor range is the most successful engineering application of fracture mechanics. The stress intensity factors are a very important parameter in fracture analysis. These factors define the stress field close to the crack tip of a crack and provide fundamental information on how the crack is going to propagate. The use of this factor can be an effective tool to analyse the fracture behaviour of cracks in the orthopedic cement.

The aim of this paper is to analyse the behaviour of cracks in the orthopedic cement by computing the SIFs. In this study, three cases are considered: crack emanating from a cavity, crack emanating from a cavity with another cavity and two cracks emanating from two cavities.

\subsection{Geometrical model}

Figure 1a shows the geometrical model used in this study. A force of $2400 \mathrm{~N}$ is applied to the structure as shown in Fig. 1b (Bergmann et al., 1993). The prosthesis is divided into three zones: proximal, median and distal and two parts: interior (right part) and exterior (left part).

The Finite element standard code ABAQUS V 6.11 (Dassault Systèmes, RI, USA) has been employed for the modeling of the problem. For the mesh generation of our model, the element type 'CPS8R' of ABAQUS code is used. It is a higher order two dimensional, 8-node element having two degrees of freedom at each node (translations in the nodal $x$ and $y$ directions), quadratic displacement behaviour and the capability of forming a triangular-shaped element, which is required at the crack-tip areas (Fig. 2a).

Due to the singular nature of the stress field in the vicinity of the crack, the singular elements, shown in Fig. 2b, are consideredat each crack-tip area, which is modeled with a finer mesh.

The model is divided into three regions of different elastic constants with isotropic material properties assumed in each region. The main regions are: implant (Ti-6Al-4V), cement (PMMA) 


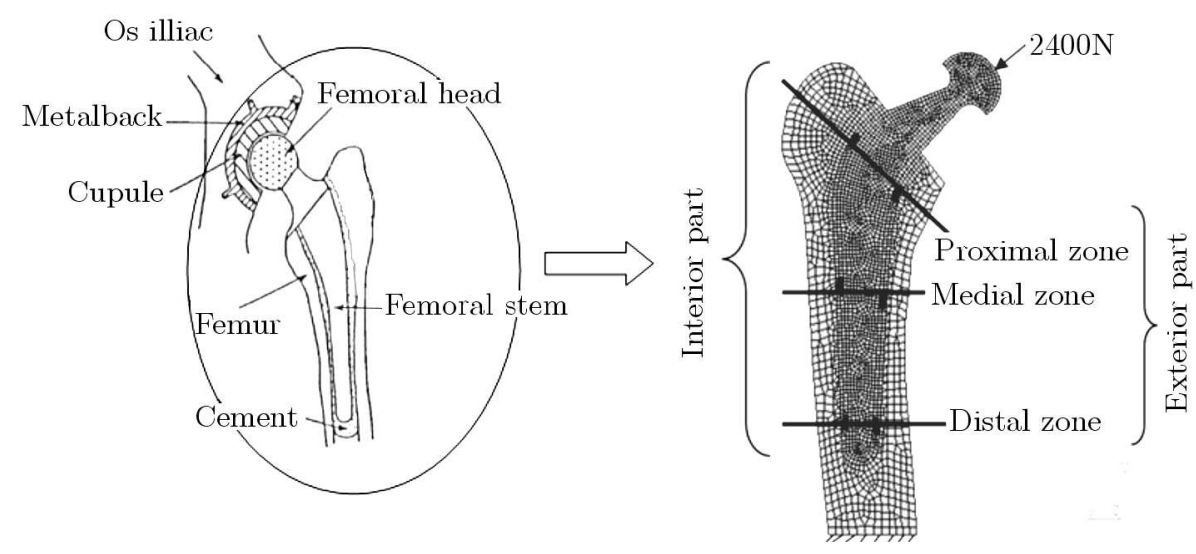

Fig. 1. (a) Geometrical model considered in the study, (b) typical mesh model
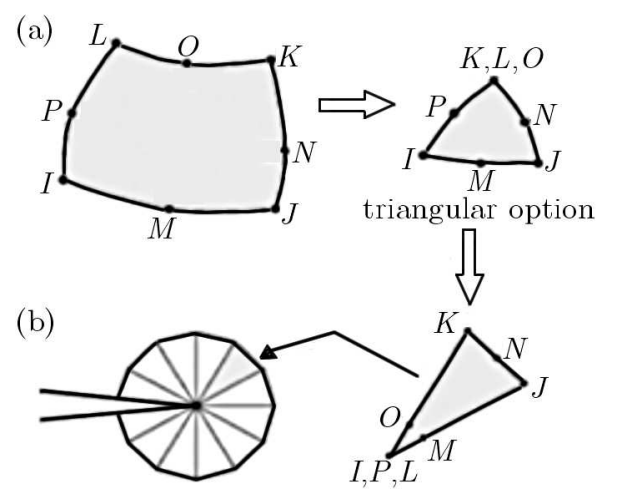

Fig. 2. (a) 'CPS8R' eight-node finite element and (b) singular option

and femoralbone. Table 1 shows the material properties used in this study (Kalapana, 2004; Flitti et al., 2010).

Table 1. Material properties

\begin{tabular}{|l|c|c|}
\hline Material & $\begin{array}{c}\text { Young's modulus } \\
E[\mathrm{MPa}]\end{array}$ & $\begin{array}{c}\text { Poisson's ratio } \\
\nu[-]\end{array}$ \\
\hline \hline Implant (Ti-6Al-4 V) & 100000 & 0.33 \\
\hline Cement (PMMA) & 2000 & 0.25 \\
\hline Femoral bone & 20000 & 0.25 \\
\hline
\end{tabular}

\section{Results and analysis}

To analyze the behaviour of cracks in the orthopedic cement, three cases are considered: the crack emanating from a cavity, interaction of the crack emanating from a cavity with another cavity and interaction of two emanating cracks from a cavity (Fig. 3).

\subsection{Case I: crack emanating from a cavity}

A crack of length $a$ emanating from a circular cavity (with diameter $D=200 \mu \mathrm{m}$ ) is supposed to exist in the orthopedic cement for different zones: proximal, medial and distal. Figure 4 shows a typical mesh model of the prosthesis. The stress intensity factors $K_{I}$ and $K_{I I}$ are obtained using the $J$-integral method. The plane stress state conditions are assumed. 


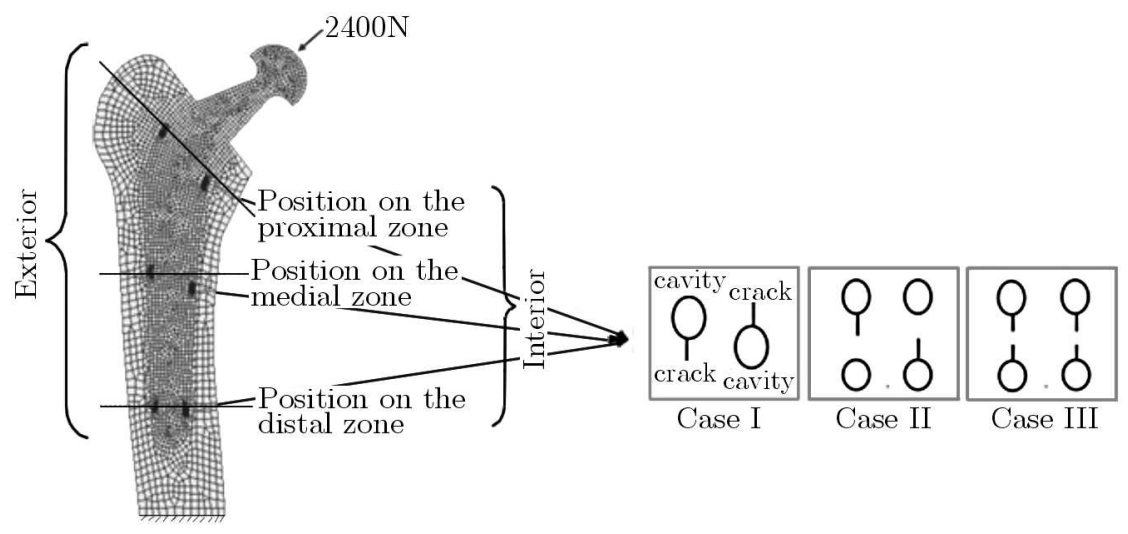

Fig. 3. Schematic representations of various cases: (a) case I: crack emanating from a cavity, (b) case II: crack emanating from a cavity with another cavity, (c) case III: two cracks emanating from two cavities

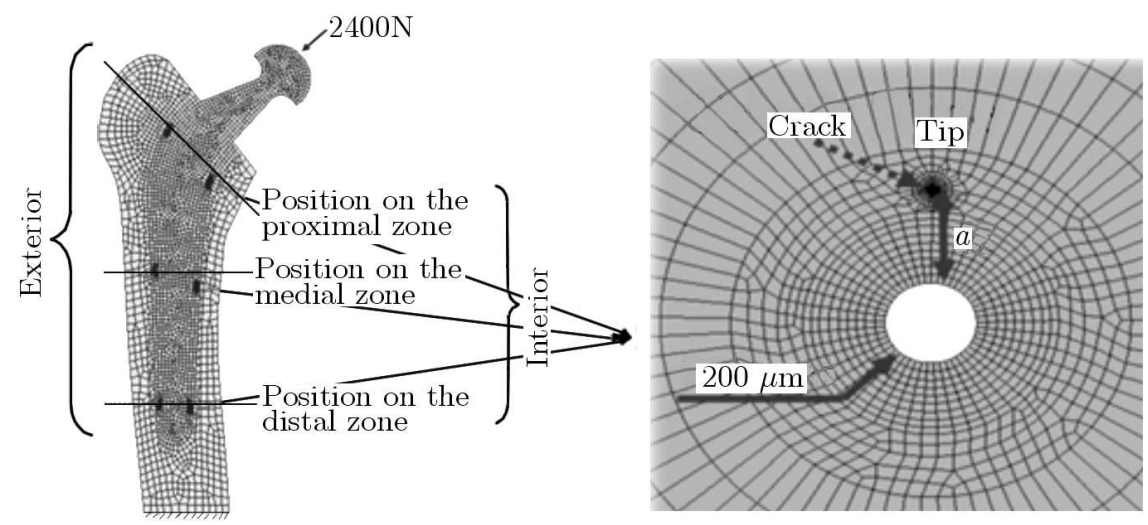

Fig. 4. Crack emanating from a cavity (case I)

Figures $5 \mathrm{a}$ and $5 \mathrm{~b}$ show respectively the variation of mode I and II stress intensity factors (SIF) in function of the crack length for different zones of the prosthesis (proximal, median and distal) and for two parts (interior and exterior).

According to Fig. 5a, it can be seen that the exterior part of the prosthesis is solicited in compression because mode I stress intensity factors are negatives in the different zones (median, distal) except for the zone proximal where mode I SIF is null.
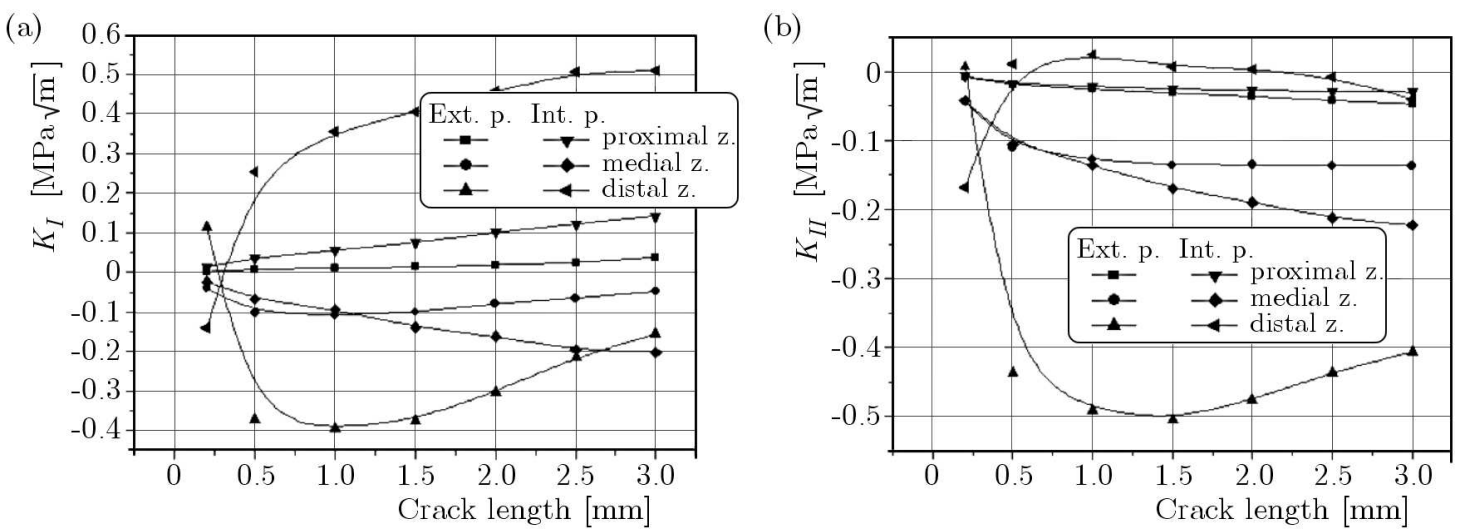

Fig. 5. Variation of SIFs $K_{I}$ and $K_{I I}$ of the crack emanating from a cavity (Case I)

In the interior part, the SIFs $K_{I}$ increases with the crack length in the distal and medial zones. In fact, the maximal SIFs values are in the distal zone $\left(0.5 \mathrm{MPa} \mathrm{m}^{1 / 2}\right)$ for a crack length 
$3 \mathrm{~mm}$. On the other hand, the SIF value in the proximal zone is $0.15 \mathrm{MPam}^{1 / 2}$ for a crack length $3 \mathrm{~mm}$. One notes that the minimal values localized in the medial zone with negative values are $-0.1 \mathrm{MPa} \mathrm{m}^{1 / 2}$ for a crack size $3 \mathrm{~mm}$. The cement in the distal zone presents the maximal fracture risk of the prosthesis compared to the other zones.

According to Fig. 5b, it can be noted that mode II stress intensity factor $\left(K_{I I}\right)$ values are null in the distal zone of the interior part for a crack length varied between 0.5 and $2.5 \mathrm{~mm}$. These results indicate that these cracks located in the distal zone can propagate according to the opening mode (mode I) with: $K_{I}>0$ and $K_{I I}=0$.

\subsection{Case II: interaction effect of the crack emanating from a cavity with another cavity}

In this case, a crack of length $a=0.5 \mathrm{~mm}$ emanating from a circular cavity of diameter $D=200 \mu \mathrm{m}$ is supposed to exist in the three zones of the prosthesis. Another cavity (of the same diameter $D$ ) is located at a distance $d$ from the crack-tip.

The prosthesis is modeled in two dimensions under plane stress conditions using isoparametric quadrilateral CPS8R elements. The crack-tip singularities are modeled using crack-tip elements. The stress intensity factors are calculated using the the $J$-integral technique. Figure 6 shows a typical mesh model of the prosthesis and the special elements around the crack tip.

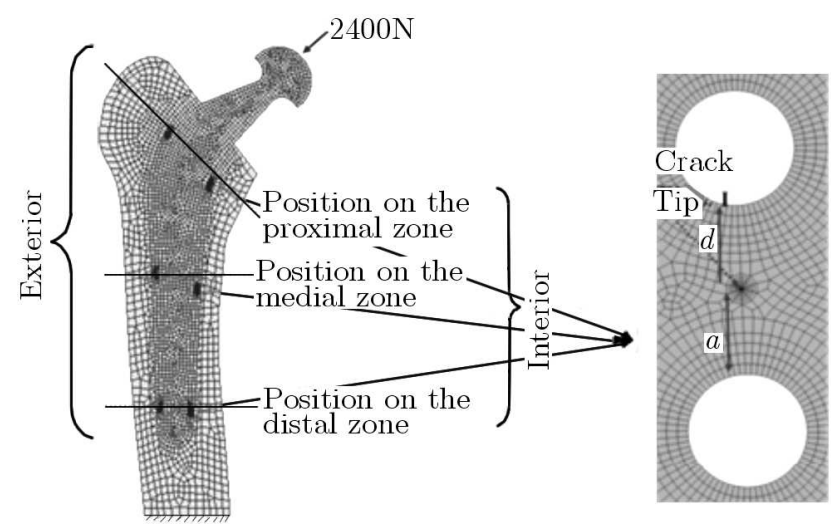

Fig. 6. Crack emanating from a cavity with another cavity (case II)
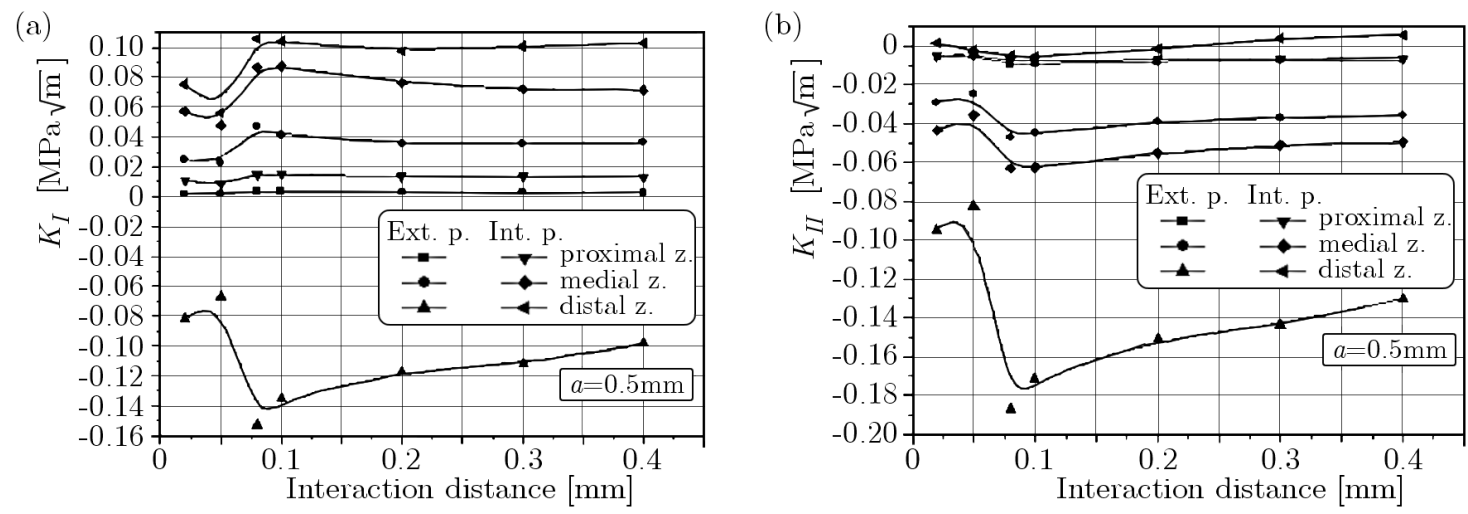

Fig. 7. Variation of SIFs $K_{I}$ and $K_{I I}$ of the crack emanating from a cavity versus the interaction distance $d$ (case II)

The results obtained are illustrated in Figs. $7 \mathrm{a}$ and $7 \mathrm{~b}$ which show the variation of SIFs $K_{I}$ and $K_{I I}$ as a function of the inter-distance $d$ between the tip of the crack emanating from a cavity and the second cavity. 
Figure 7a shows that whatever the zone of initiation of the crack (except for the distal zone of the exterior share), SIF $K_{I}$ is positive. This shows that such a position of the crack leads to the opening of the crack. Indeed, it depends on the intensity of the stress field in which the crack is located. For a distance $d<0.1 \mathrm{~mm}$, the SIF increases in a remarkable way. Beyond this distance, the variation of FIC $K_{I}$ is independent of the distance $d$. In the distal zone of the exterior part, SIF $K_{I I}$ is negative. This shows that when the cavity is distant, the extension risk of the crack per opening is almost null. In Fig. $7 \mathrm{~b}$, for $d>0.1 \mathrm{~mm}$, the values of SIF $K_{I I}$ are independent of the distance $d$. In the distal zone, this factor increases with an increase in the distance $d$.

\subsection{Case III: interaction effectof two cracks emanating from two cavities}

In order to determine the interaction effect of two cracks emanating from a cavity, we choose a crack of length $a$ emanating from a circular cavity of diameter $D$. Another crack of length $a$ is supposed to emanate from another cavity (of the same diameter $D$ ).

In Fig. 8, $a$ and $a^{\prime}$ are the lengths of two cracks. The inter-distance between the two cracks is given by the parameter $d$.

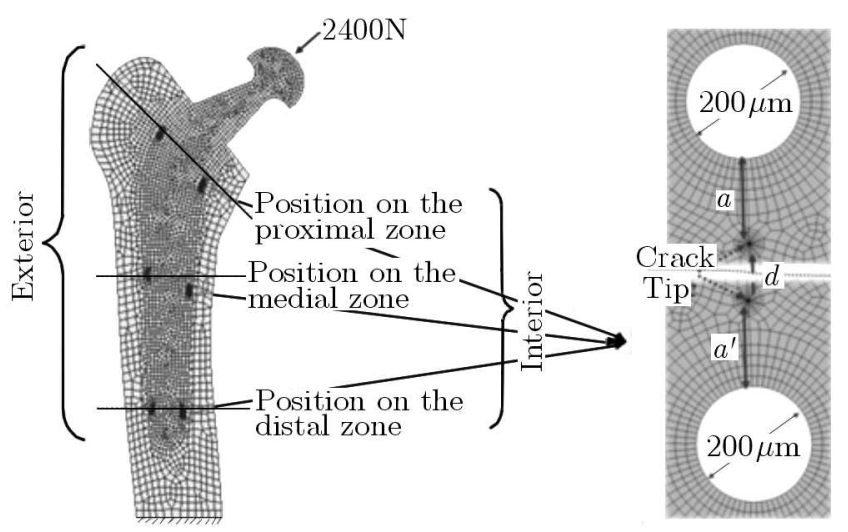

Fig. 8. Two cracks emanating from two cavities (case III)

Figures 9a and 9b show respectively modes I and II stress intensity factors (SIF) of the main crack emanating from a cavity as a function of the distance $d$ between the two cracks tips. The SIFs $K_{I}$ and $K_{I I}$ are evaluated for three zones of prosthesis (proximal, median and distal)and for two parts (interior and exterior).

The results obtained in Fig. 9a show that:

- For distance $d<0.1 \mathrm{~mm}$, the SIF $K_{I}$ increases with reduction in the distance $d$. This increase is observed in the three zones of the prosthesis, except for the proximal zone of the exterior part (where mode I SIF is null) and in the distal zone of the exterior part (where mode I SIF is negative). The negative values of $K_{I}$ indicate that the distal zone is solicited in compression.

- The important values of $K_{I}$ are observed in the distal zone of the interior part, for $d \approx 0.1 \mathrm{~mm}$. In all the zones, these values are stabilized for $d>0.2 \mathrm{~mm}$.

In linear elastic fracture mechanics (LEFM), positive and negative values of $K_{I I}$ indicate the direction of crack propagation. This direction is opposite to the sign of $K_{I I}$ (Souiyah et al., 2012; Alshoaibi Abdulnaser and Ariffin, 2008). In Fig. 9b, the important values of $K_{I I}$ (absolute values) are observed in the distal zone of the interior part, for $d \approx 0.1$. Beyond this distance, the values of $K_{I I}$ (absolute values) decrease until the distance $d=0.2 \mathrm{~mm}$ is reached. For $d>0.2 \mathrm{~mm}$, the SIFs $K_{I I}$ takes stable values. 
The negative values of $K_{I I}$ (with $K_{I}<0$ ) indicate that the distal zone of the interior part is solicited in compression.
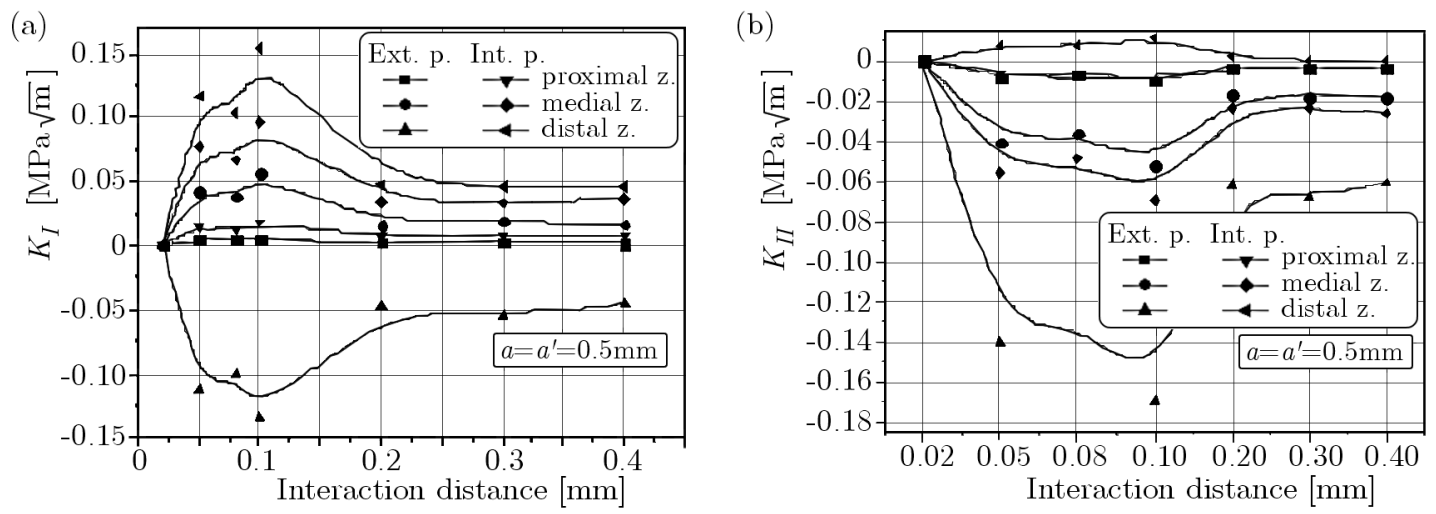

Fig. 9. Variation of SIFs $K_{I}$ and $K_{I I}$ of the main crack emanating from two cavities versus the distance $d$ between two cracks (case III)

\section{Conclusion}

The predicted values of SIFs for cracks behaviour in the orthopedic cement using the 2D finite element method are presented. In order to obtain a better approximation of the stress field near the crack tip, special quarter point finite elements are used. The analysis of the results obtained shows that a crack initiated from a micro-cavity or from bone debris in the distal zone of the external and interior parts of the cement can be propagated at the same time by opening and shearing of its lips; i.e. under mixed modes. It is contrary to the crack initiated in the proximal zone, which cannot be propagated. The mechanical behaviour of cracks in the medial zone depends on the crack initiation position.

\section{References}

1. ABAQUS V 6-11, User Guide, Cornell University, 2004

2. Alshoaibi Abdulnaser M., Ariffin A.K., 2008, Fatigue life and crack path prediction in 2D structural components using an adaptive finite element strategy, International Journal of Mechanical and Materials Engineering, 3, 1, 97-104

3. Bachir Bouiadjra B., Belarbi A., Benbarek S., Achour T., Serier B., 2007, FE analysis of the behaviour of microcracks in the cement mantle of reconstructed acetabulum in the total hip prosthesis, Computational Materials Science, 40, 485-491

4. Benbarek S., Bachir Bouiadjra B., Achour T., Belhouari M., Serier B., 2007, Finite element analysis of the behaviour of crack emanating from microvoid in cement of reconstructed acetabulum, Materials Science and Engineering A, 457, 385-391

5. Benbarek S., Bachir Bouiadjra B., Bouziane M.M., Achour T., Serier B., 2013, Numerical analysis of the crack growth path in the cement mantle of the reconstructed acétabulum, Materials Science and Engineering C, 33, 543-549

6. Benouis A., Boulenouar A., Benseddiq N., Serier B., 2015, Numerical analysis of crack propagation in cement PMMA: application of SED approach, Structural Engineering and Mechanics, $\mathbf{5 5}, 93-109$

7. Benouis A., Serier B., Benbarek S., 2015, Influence of porosity on the behaviour of cement orthopaedic of total hip prosthesis, Advances in Biomechanics and Applications, 2, 1, 1-10 
8. Bergmann G., Graichen F., Rohlmann A., 1993, Hip joint loading during walking and running, measured in two patientsm, Journal of Biomechanics, 26, 969-990

9. Bouziane M.M., Bachir Bouiadjra B., Benseddiq N., Tabeti E.M.H., Serier B., BenBAREK S., 2013, The effects of cracks emanating from micro-void and bone inclusion in cemented total hip replacement, Advances in Bio-Mechanical Systems and Materials, Advanced Structured Materials, Books, Springer

10. Flitti A., Ouinas D., Bachir Bouiadjra B., Benderdouche N., 2010, Effect of the crack position in the cement mantle on the fracture behaviour of the total hip prosthesis, Computational Materials Science, 49, 598-602

11. Hertzler J., Miller M.A., Mann K.A., 2002, Fatigue crack growth rate does not depend on mantle thickness: an idealized cemented stem construct under torsional loading, Journal of Orthopaedic Research, 20, 676-682

12. Jasty M., Maloney W.J., Bragdon, C.R. O’Connor D.O., Haire T., Harris W.H., 1991, The initiation of failure in cemented femoral components of hip arthroplasties, Journal of Bone and Joint Surgery, 73, 551-558

13. Kalpana S.K., 2004, Biomaterials in total joint replacement, Colloids and Surfaces B: Biointerfaces, 39, 133-142

14. Leroy R., 1991, Etude et comportement non-uniforme de l'interface entre implant Fémorale et liant poymérique dans le cas de prothèse totale de hanche, Thèse de doctorat, Université Tours

15. Li C., Granger C., Del Schuttte H.R., Biggers S.B. Jr., Kennedy J.M., Latour R.A., 2002, Progressive failure analysis of laminated composite femoral prostheses for total hip arthroplasty, Journal of Biomaterials, 23, 4249-4262

16. Oshrour A.A., Davoodi M.M., Abu Osman N.A., Yau Y.H., Tarlochan F., Wan Abas W.A.B., 2013, Finite element analysis of circumferential crack behavior in cement-femoral prosthesis interface, Materials and Design, 49, 96-102

17. Ouinas D., Flliti A., Sahnoun M., Benbarek S., Taghezout N., 2012, Fracture behavior of the cement mantle of reconstructed acetabulum in the presence of a microcrack emanating from a microvoid, International Journal of Materials Engineering, 2 , 90-104

18. Poitout D., 1992, Biomécanique orthopédique, Editions Masson

19. Sahli A., Benbarek S., Bachir Bouiadjra B., Bouziane M.M., 2014, Effects of interaction between two cavities on the bone cement damage of the total hip prothesis, Mechanics and Mechanical Engineering, 18, 2, 107-120

20. Souiyah M., Muchtar A., Ariffin A.K., Malek A., Fadhel M.I., Basem Abu Zneid, 2012, Finite element model of crack growth under mixed mode loading, International Journal of Materials Engineering, 2, 67-74

21. Taylor D., Hazenberg J.G., Lee T.C., 2003, The cellular transducer in damage-stimulated bone remodelling: a theoretical investigation using fracture mechanics, Journal of Theoretical Biology, 225, 65-75 